\title{
Molecular docking and dynamic simulation of Olea europaea and Curcuma Longa compounds as potential drug agents for targeting Main-Protease of SARS-nCoV2
}

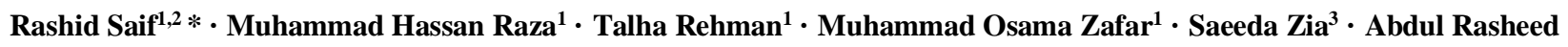 \\ Qureshi $^{4}$ \\ ${ }^{1}$ Institute of Biotechnology, Gulab Devi Educational Complex, Lahore, Pakistan. \\ 2 Decode Genomics, Punjab University Employees Housing Scheme (II), Lahore, Pakistan. \\ 3 Department of Sciences and Humanities, National University of Computer and Emerging Sciences, Lahore, Pakistan. \\ ${ }^{4}$ Out-Patients Department-Pulmonology, Gulab Devi Chest Hospital, Ferozepur Road, Lahore, Pakistan. \\ *Corresponding author: Rashid Saif, Institute of Biotechnology, Gulab Devi Educational Complex, Lahore, Pakistan. Tel: +92- \\ 321-7107501E-mail: rashid.saif37@gmail.com
}




\begin{abstract}
One of the main reasons of rapidly growing cases of COVID-19 pandemic is the unavailability of approved therapeutic agents. Therefore, it is urgently required to find out the best drug by all means. Aim of the current study is to test the anti-viral drug potential of many of the available olive and turmeric compounds that can be used as potential inhibitors against one of the target proteins of SARS-nCoV2 named Main protease (Mpro/3CLpro). Molecular docking of thirty olive and turmeric compounds with target protein was performed using Molecular Operating Environment (MOE) software, out of these 19 ligands were selected for redocking using PyRx to validate MOE results and to determine the best ligand-protein interaction energies. Molecular dynamics simulation was performed on best 7 docked complexes by NAMD/VMD to determine the stability of the ligand-protein complex. Out of the thirty drug agents, 6 ligands do not follow the Lipinski rule of drug likeliness by violating two or more rules while remaining 24 obey the rules and included for the downstream analysis. We found that Demethyloleoeuropein, Oleuropein, Rutin, Neuzhenide, Luteolin-7-rutinoside, Curcumin and Tetrehydrocurcumin gave best docking score and form much stable complexes during simulation. Our predictions suggest that these ligands have the potential inhibitory effects on Mpro of SARS-nCoV2, so, these herbal plants would be helpful in harnessing COVID-19 infection as home remedy with no serious known side effects. Further, in-vivo experimental studies are needed to validate the inhibitory properties of these compounds against the current and other target proteins in SARS-nCoV2.
\end{abstract}

Keywords Curcuma longa $\cdot$ COVID-19 $\cdot$ Main protease $\cdot$ Molecular docking $\cdot$ MOE software $\cdot$ PyRx $\cdot$ Molecular dynamic simulation $\cdot$ Olea europaea $\cdot \mathrm{SARS}-\mathrm{nCoV} 2 \cdot \mathrm{NAMD}$ 


\section{Introduction}

Coronaviruses (CoVs) are group of positive sense RNA viruses that cause upper respiratory tract infection, hepatic diseases, multiple organ failure and gastrointestinal disorder in both animals and humans (Brian and Baric 2005; Kupferschmidt 2013; Peiris et al. 2003; Renu et al. 2020).

In December 2019, patients with new kind of disease having symptoms like pneumonia were reported in Wuhan, Hubei Province of China (Lee and Hsueh 2020; Zhu et al. 2020). This infectious agent was recognized as a new strain of corona virus because it shares $70 \%$ similarity with SARS-CoV-1 (severe acute respiratory syndrome) and was temporarily given a name 2019-nCov (Hui et al. 2020). Virus has a characteristic human to human transmission and causes respiratory tract infection that ultimately leads to multiple organ failure (Paraskevis et al. 2020; Renu et al. 2020; Wang et al. 2020).

World Health Organization (WHO) officially named the virus as SARS-nCoV2 (disease COVID-19) and on March 31, 2020 declared the disease a pandemic (Cucinotta and Vanelli 2020). Until Jan 2021, COVID-19 caused more than 2.46M deaths and 111M confirmed cases worldwide ((WHO) 2020). SARS-nCoV2 (COVID-19) belongs to the family of Coronaviridae and is the seventh member of genus Betacoronavirus (Coronaviridae Study Group of the International Committee on Taxonomy of 2020).

SARS-nCoV2 infects the host cell by attaching to ACE-2 receptor through its spike protein (Renu et al. 2020). After binding, the virus moves into the cell and starts its replication. Besides spike protein, $\mathrm{M}^{\text {pro }}$ (main protease) / $3 \mathrm{CL}^{\text {pro }}$ and $\mathrm{PL}^{\text {pro }}$ (recognized as potential drug targets) also play main role in viral replication (Xu et al. 2020). Until now, there is no approved drug against COVID-19; however, supporting drugs like remedsivir, nelfinavir and hydroxychloroquine provide immunomodulatory action and prevents organ damage (Xu et al. 2020).

The main target of drugs against which scientists are focusing these days is $\mathrm{M}^{\text {pro }}$ (main protease), because main protease of SARS-nCoV2 shares 96\% similarity with SARS-CoV-1 (Paraskevis et al. 2020). COVID-19's main target, $\mathrm{M}^{\mathrm{pro}} / 3 \mathrm{CL}^{\mathrm{pro}}$, has been successfully crystallized, submitted and repositioned in PDB (PDB ID: 6M2N) by $\mathrm{Su}$ et al. (2020). This protein represents a potential drug target and its inhibition results in the blockage of replication and infectious cycle of Corona virus (Xue et al. 2008).

Due to lack of specific drug against COVID-19, there is an ongoing trend of usage of herbs and herbal extracts because these are used as conventional antiviral medicines ( $\mathrm{Li}$ and Peng 2013).

In present study, we will investigate the compounds of Olea europaea (olive) and Curcuma longa (turmeric) as the potential inhibitors of COVID-19 by computer-aided drug design (CADD) (Yu and MacKerell 2017). Molecular operating environment (MOE), PyRx and NAMD are used in this in-silico studies of Docking and MD Simulation. This investigation will provide other researchers the opportunity to identify best drugs to treat COVID-19.

\section{Materials and Methods}

\subsection{Selection of Medicinal Herbs}

\subsubsection{Olea europaea (Olive)}

Olea europaea, which is known for its great therapeutic potential, is widely recommended for treating COVID-19 infection because of its compounds, like oleuropein, that have antiviral properties (Micol et al. 2005). For centuries, it is being used in North African and Asian areas as a food and conventional medication due to Islamic conviction (Ali et al. 2018). Olea europaea extracts have antiviral, antiepileptic, antioxidant, anti-erythrogenic, germicide, cancer preventing, gastroprotective, wound mending, immunosuppressive, blood glucose lowering and pain relieving properties (Hashmi et al. 2015). Nearly its 25 bioactive compounds have been reported in olive extract as cited in different literatures (Boskou et al. 2015; Ghanbari et al. 2012; Hashmi et al. 2015). The structure of Olea europaea compounds are given in Fig. 1. 


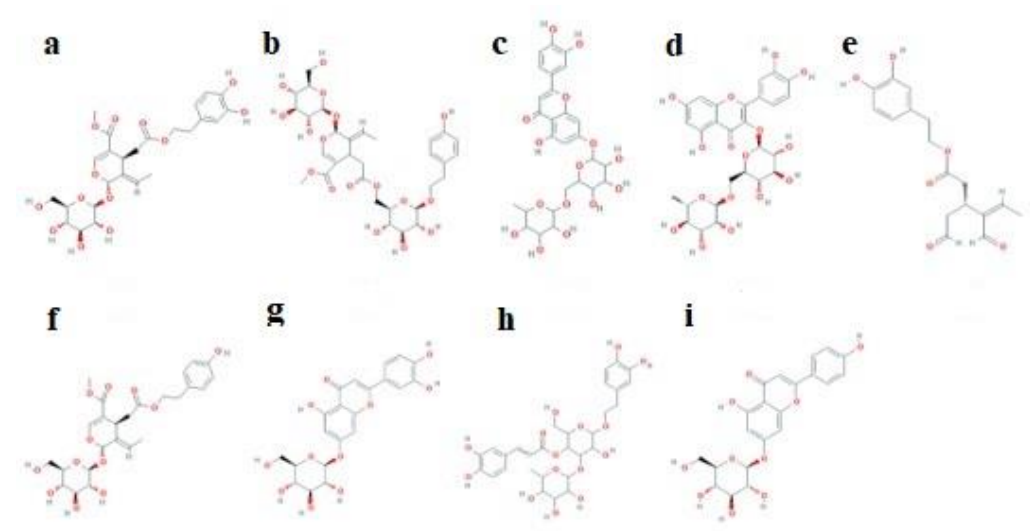

Fig. 1 Chemical structure of major compounds of Olea europaea. a Oleuropein b Neuzhenide c Luteolin 7-rutinoside d Rutin e Deacetoxyoleuropein aglycone $\mathbf{f}$ Ligstroside $\mathbf{g}$ Cynaroside (Luteolin-7-glucoside) h Verbascoside $\mathbf{i}$ Cosmosin

The chemical properties of compounds were taken from PubChem. Different scientist performed various experiments to obtain a set of properties and then submitted those in PubChem and other similar chemical databases. The chemical properties of Olea europaea compounds are given in (Table 1).

Table 1 The chemical parameters of Olea europaea compounds. TPSA= topological polar surface area, $\mathrm{H}$-donn= hydrogen bond donor, $\mathrm{H}-$ acc $=$ hydrogen bond acceptor, $\mathrm{RB}=$ rotatable bond

\begin{tabular}{|c|c|c|c|c|c|c|c|c|c|}
\hline Ligands & $\begin{array}{c}\text { Molecular } \\
\text { Weight } \\
(\mathrm{g} / \mathrm{mol})\end{array}$ & $\begin{array}{l}\text { PubChem } \\
\text { CID }\end{array}$ & Toxicity & $\begin{array}{c}\log \\
P\end{array}$ & $\begin{array}{c}\mathrm{H}- \\
\text { donn }\end{array}$ & $\begin{array}{l}\mathrm{H}- \\
\text { acc }\end{array}$ & RB & TPSA & $\begin{array}{l}\text { Molecular } \\
\text { Formula }\end{array}$ \\
\hline Oleuropein & 540.5 & 5281544 & $\mathrm{NO}$ & -0.4 & 6 & 13 & 11 & $202 \AA^{2}$ & $\mathrm{C}_{25} \mathrm{H}_{32} \mathrm{O}_{13}$ \\
\hline Neuzhenide & 686.7 & 6440999 & NO & -2.2 & 8 & 17 & 14 & $261 \AA^{2}$ & $\mathrm{C}_{31} \mathrm{H}_{42} \mathrm{O}_{17}$ \\
\hline luteolin 7rutinoside & 594.5 & 12315422 & NO & -1.1 & 9 & 15 & 6 & $245 \AA^{2}$ & $\mathrm{C}_{27} \mathrm{H}_{30} \mathrm{O}_{15}$ \\
\hline Rutin & 610.5 & 5280805 & irritant & -1.3 & 10 & 16 & 6 & $266 \AA^{2}$ & $\mathrm{C}_{27} \mathrm{H}_{30} \mathrm{O}_{16}$ \\
\hline Demethyloleoeuropein & 526.5 & 6450302 & NO & -0.8 & 7 & 13 & 10 & $213 \AA^{2}$ & $\mathrm{C}_{24} \mathrm{H}_{30} \mathrm{O}_{13}$ \\
\hline Ligstroside & 524.5 & 14136859 & NO & -0.1 & 5 & 12 & 11 & $181 \AA^{2}$ & $\mathrm{C}_{25} \mathrm{H}_{32} \mathrm{O}_{12}$ \\
\hline Verbascoside & 624.6 & 354009 & NO & -0.5 & 9 & 15 & 11 & $245 \AA^{2}$ & $\mathrm{C}_{29} \mathrm{H}_{36} \mathrm{O}_{15}$ \\
\hline $\begin{array}{l}\text { Cosmosin (apigenin 7- } \\
\text { glucoside) }\end{array}$ & 432.4 & 5280704 & NO & -0.1 & 6 & 10 & 4 & $166 \AA^{2}$ & $\mathrm{C}_{21} \mathrm{H}_{20} \mathrm{O}_{10}$ \\
\hline Luteolin & 286.24 & 5280445 & irritant & 1.4 & 4 & 6 & 1 & $107 \AA^{2}$ & $\mathrm{C}_{15} \mathrm{H}_{10} \mathrm{O}_{6}$ \\
\hline luteolin7glucoside & 448.4 & 5280637 & NO & 0.5 & 7 & 11 & 4 & $186 \AA^{2}$ & $\mathrm{C}_{21} \mathrm{H}_{20} \mathrm{O}_{11}$ \\
\hline $\begin{array}{l}\text { Deacetoxyoleuropein } \\
\text { aglycone }\end{array}$ & 320.3 & 101102227 & NO & 1.1 & 2 & 6 & 10 & $101 \AA^{2}$ & $\mathrm{C}_{17} \mathrm{H}_{20} \mathrm{O}_{6}$ \\
\hline Chlorogenic acid & 354.31 & 1794427 & irritant & -0.4 & 6 & 9 & 5 & $165 \AA^{2}$ & $\mathrm{C}_{16} \mathrm{H}_{18} \mathrm{O}_{9}$ \\
\hline luteolin-4'-o-glucoside & 448.4 & 5319116 & NO & 0.5 & 7 & 11 & 4 & $186 \AA^{2}$ & $\mathrm{C}_{21} \mathrm{H}_{20} \mathrm{O}_{11}$ \\
\hline Apigenin & 270.24 & 5280443 & irritant & 1.7 & 3 & 5 & 1 & $87 \AA^{2}$ & $\mathrm{C}_{15} \mathrm{H}_{10} \mathrm{O}_{5}$ \\
\hline Quercetin & 302.23 & 5280343 & Irritant & 1.5 & 5 & 7 & 1 & $127 \AA^{2}$ & $\mathrm{C}_{15} \mathrm{H}_{10} \mathrm{O}_{7}$ \\
\hline Ferulic Acid & 194.18 & 445858 & Irritant & 1.5 & 2 & 4 & 3 & $66.8 \AA^{2}$ & $\mathrm{C}_{10} \mathrm{H}_{10} \mathrm{O}_{4}$ \\
\hline Flavylium & 207.25 & 145858 & NO & 0 & 0 & 0 & 1 & $1 \AA^{2}$ & $\mathrm{C}_{15} \mathrm{H}_{11} \mathrm{O}^{+}$ \\
\hline Sinapic Acid & 224.21 & 637775 & irritant & 1.5 & 2 & 5 & 4 & $76 \AA^{2}$ & $\mathrm{C}_{11} \mathrm{H}_{12} \mathrm{O}_{5}$ \\
\hline Homovanillic Acid & 182.17 & 1738 & irritant & 0.4 & 2 & 4 & 3 & $66.8 \AA^{2}$ & $\mathrm{C}_{9} \mathrm{H}_{10} \mathrm{O}_{4}$ \\
\hline Cinamic Acid & 255.4 & 5372020 & NO & -0.6 & 2 & 5 & 6 & $114 \AA^{2}$ & $\mathrm{C}_{11} \mathrm{H}_{13} \mathrm{NO}_{2} \mathrm{~S}_{2}$ \\
\hline Vanillic Acid & 168.15 & 8468 & irritant & 1.4 & 2 & 4 & 2 & $66.8 \AA^{2}$ & $\mathrm{C}_{8} \mathrm{H}_{8} \mathrm{O}_{4}$ \\
\hline Tyrosol & 138.16 & 10393 & irritant & 0.4 & 2 & 2 & 2 & $40.5 \AA^{2}$ & $\mathrm{C}_{8} \mathrm{H}_{10} \mathrm{O}_{2}$ \\
\hline Protocatehuic acid & 154.12 & 72 & Irritant & 1.1 & 3 & 4 & 1 & $77.8 \AA^{2}$ & $\mathrm{C}_{7} \mathrm{H}_{6} \mathrm{O}_{4}$ \\
\hline Hydroxytyrosol & 154.16 & 82755 & Irritant & -0.7 & 3 & 3 & 2 & $60.7 \AA^{2}$ & $\mathrm{C}_{8} \mathrm{H}_{10} \mathrm{O}_{3}$ \\
\hline $\begin{array}{l}\text { 4-Hydroxy Benzoic } \\
\text { Acid }\end{array}$ & 138.12 & 135 & Irritant & 1.6 & 2 & 3 & 1 & $57.5 \AA^{2}$ & $\mathrm{C}_{7} \mathrm{H}_{6} \mathrm{O}_{3}$ \\
\hline
\end{tabular}




\subsubsection{Curcuma longa (Turmeric)}

Curcuma longa is known as a powerful natural healer. For quite a long time, it is being utilized in Asia as a traditional medicine (Bhowmik et al. 2008). Compounds in olive have antiviral, antineoplastic, antiprotozoal, microbicidal, fungicidal, COX-inhibitor, antioxidant and antivenin properties (Bhowmik et al. 2008). Five active compounds are present in turmeric (Chattopadhyay et al. 2003; Niranjan and Prof 2008) and their structures are given in Fig. 2.
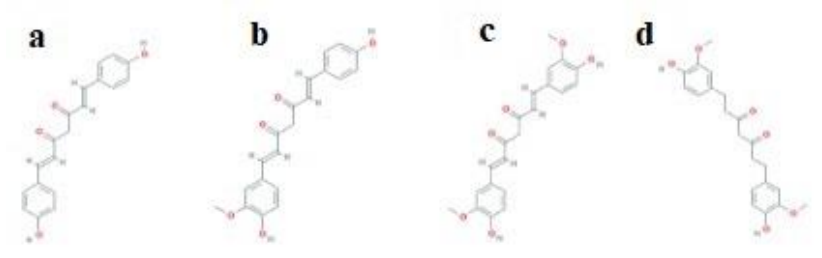

Fig. 2 The chemical structures of major compounds of Curcuma longa. a Bisdemethoxycurcumin b Demethoxycurcumin c Curcumin d Tetrahydrocurcumin

As Curcuma longa compounds are recognized for reducing effect of inflammation causing cytokinin (such as interleukin 6) but this herb is also reported for causing dermatitis. To predict drug potential, their properties are taken from PubChem database. The chemical properties of Curcuma longa compounds are given in (Table 2).

Table 2 Chemical properties of Turmeric compounds. TPSA= topological polar surface area, H-donn= hydrogen bond donor, $\mathrm{H}-\mathrm{acc}=$ hydrogen bond acceptor, Env= environment, Haz= hazard

\begin{tabular}{|c|c|c|c|c|c|c|c|c|c|}
\hline Ligands & $\begin{array}{c}\text { Molecular } \\
\text { Weight } \\
(\mathrm{g} / \mathrm{mol})\end{array}$ & $\begin{array}{l}\text { PubChem } \\
\text { CID }\end{array}$ & Toxicity & $\begin{array}{c}\text { Log } \\
P\end{array}$ & $\begin{array}{c}\mathrm{H}- \\
\text { donn }\end{array}$ & $\begin{array}{l}\mathrm{H}- \\
\text { acc }\end{array}$ & $\begin{array}{c}\text { Biological } \\
\text { Activity }\end{array}$ & TPSA & $\begin{array}{c}\text { Molecular } \\
\text { Formula }\end{array}$ \\
\hline Curcumin & 368.4 & 969516 & irritant & 3.2 & 2 & 6 & $\begin{array}{l}\text { Antibacterial, } \\
\text { Antiviral }\end{array}$ & $93.1 \AA^{2}$ & $\mathrm{C}_{21} \mathrm{H}_{20} \mathrm{O}_{6}$ \\
\hline Bisdemethoxycurcumin & 308.3 & 5315472 & irritant & 3.3 & 2 & 4 & Antioxidant & $74.6 \AA^{2}$ & $\mathrm{C}_{19} \mathrm{H}_{16} \mathrm{O}_{4}$ \\
\hline Demethoxycurcumin & 338.4 & 5469424 & $\begin{array}{l}\text { Env. } \\
\text { Haz. }\end{array}$ & 3.3 & 2 & 5 & Antioxidant & $83.8 \AA^{2}$ & $\mathrm{C}_{20} \mathrm{H}_{18} \mathrm{O}_{5}$ \\
\hline Tetrahydrocurcumin & 372.4 & 124072 & NO & 2.8 & 2 & 6 & $\begin{array}{l}\text { Anti- } \\
\text { inflammatory }\end{array}$ & $93.1 \AA^{2}$ & $\mathrm{C}_{21} \mathrm{H}_{24} \mathrm{O}_{6}$ \\
\hline Ar-turmeron & 216.32 & 160512 & irritant & 4 & 0 & 1 & Antivenom & $17.1 \AA^{2}$ & $\mathrm{C}_{15} \mathrm{H}_{20} \mathrm{O}$ \\
\hline
\end{tabular}

\subsection{Selection of Targeted Protein}

\subsubsection{Main Protease}

$\mathrm{M}^{\mathrm{pro}} / 3 \mathrm{c}^{\mathrm{pro}}$ (PDB ID: 6M2N) is the key enzyme in SARS-nCoV2 that has a main role in viral replication and transcription (Jin et al. 2020). This enzyme is involved in producing Nsps (non-structural proteins) which then assemble the viral protein. So by targeting $\mathrm{M}^{\text {pro }}$, viral replication can be halted (Mengist et al. 2020). 
Table 3 Crystallographic properties of enzyme (Mro)

\begin{tabular}{|c|c|c|c|c|c|c|c|c|c|c|}
\hline Enzyme & $\begin{array}{l}\text { PDB } \\
\text { ID }\end{array}$ & Classification & Virus & $\begin{array}{c}\text { Expression } \\
\text { system }\end{array}$ & Resolution & Method & $\begin{array}{c}\text { Total } \\
\text { structure } \\
\text { weight } \\
\text { (DA) }\end{array}$ & Chain & $\begin{array}{l}\text { Atom } \\
\text { count }\end{array}$ & $\begin{array}{l}\text { Active } \\
\text { site } \\
\text { residues }\end{array}$ \\
\hline $\begin{array}{l}\text { Main } \\
\text { protease }\end{array}$ & $6 \mathrm{M} 2 \mathrm{~N}$ & $\begin{array}{l}\text { Viral } \\
\text { Protein }\end{array}$ & $\begin{array}{l}\text { SARS- } \\
\text { nCOV2 } \\
\text { (Severe } \\
\text { acute } \\
\text { respiratory } \\
\text { syndrome) }\end{array}$ & $\begin{array}{l}\text { Escherichia } \\
\text { coli BL21 }\end{array}$ & $2.20 \AA$ & $\begin{array}{l}\text { X-RAY } \\
\text { Diffraction }\end{array}$ & $\begin{array}{l}136.38 \\
\mathrm{kDa}\end{array}$ & $\begin{array}{l}\text { A, B, } \\
\text { C, D }\end{array}$ & 9544 & $\begin{array}{l}\text { THR24, } \\
\text { THR26, } \\
\text { PHE140, } \\
\text { ASN142, } \\
\text { GLY143, } \\
\text { CYS145, } \\
\text { HIS163, } \\
\text { HIS164, } \\
\text { GLU166, } \\
\text { HIS172 }\end{array}$ \\
\hline
\end{tabular}

\subsection{Molecular Docking using MOE}

The molecular docking was performed by Molecular Operating Environment (MOE) software. It is a drug discovery software that can be used for checking protein-ligand interactions and for drug likeness analyses. MOE is a platform that incorporates visualization of results, modeling, simulations of structures and methodology development in one package (Vilar et al. 2008).

\subsubsection{Preparation of Ligands}

Several databases are available to obtain the desired ligand e.g. DrugBank, Zinc, PubChem, Asinex ChEMBL, Merck, Enamine etc. These ligands can either be downloaded in sdf format or can be sketched in MOE interface by using Builder Mode. After sketching, the partial charges were added by using compute in MOE. Once the charges were added the prepared ligand is then saved as MDB file as shown in Fig. 3.

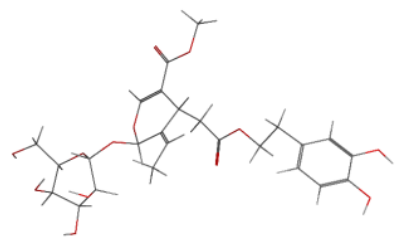

Fig. 3 Prepared ligand of Oleuropein

\subsubsection{Preparation of Target Protein}

Protein data bank is the source of our target protein. PDB file 6M2N was downloaded and opened in MOE (Omar 2010).

\section{a) Removal of Water, Inhibitor and Repeated Chains}

The already attached ligand was removed to make active site accessible for new ligand. The water molecules were also removed from the protein surface so that the interacting region would not be hidden during docking. The repeated chains of $\mathrm{M}^{\text {pro }}$ were also removed to avoid complications during docking.

\section{b) Correction of Protein Structure}

Errors and missing atoms in structure were then corrected and added by using the feature of structure preparation in MOE. For correction of structure, first Protein module of MOE was selected. Afterwards, by selecting structure and 
preparation option, the new window appeared and from that protonate $3 D$ module was selected and in the last step, the correction option corrected our desired protein's structure.

\section{c) Active Site Finder}

MOE main interface was used to open compute and after that Site Finder was selected. We chose apply option from new interface which gave number of different chains that could be the possible active site of target protein. From literature survey or Pymol, we selected the chain which had the sequence of active site residues. If the sequence of active site is unknown, then blind docking will prefer (it is better to use first 3 chains). No Centers and atoms and backbone option were selected from Render and isolate module respectively. Then by clicking dummies option, the dummy atoms were created. This prepared protein structure is displayed in Fig. 4.

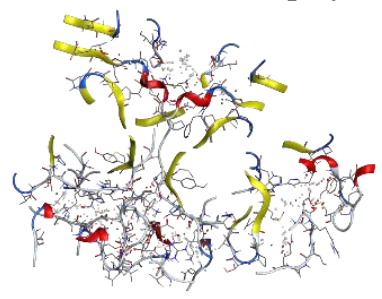

Fig. 4 Prepared protein (M-pro)

\subsubsection{Docking and Surface Maps}

Docking was performed to determine the possible interaction between ligand and active site of target protein $6 \mathrm{M} 2 \mathrm{~N}$ (Hewlings and Kalman 2017). A new dock window was opened when we selected dock from compute option in MOE interface. Dummy atoms in site module was selected (from which the docking was performed). We uploaded ligand file from ligand $m d b$ file module which was previously prepared. In the end command was run. Surface and maps module in MOE focused and isolated the point where ligand attached to protein with minimum energy.

\subsection{Redocking of molecules using PyRx}

To further validate the results, it is necessary to perform docking with another software and for this purpose we selected PyRx which is virtual screening software incorporated with two built-in features and these are vina wizard ( Auto-dock vina) to perform docking and open Babel to convert files (Dallakyan and Olson 2015). This PyRx works on graphical user interface

\subsubsection{Protein Preparation}

Protein of interest was first downloaded from protein data bank (PDB) and was further processed using following softwares

\section{a) Pre-processing via DS}

For pre-processing of protein, the discovery studio (DS) visualizer was used to remove all repeated chains, heteroatoms, water molecules and already attached ligand. Only chain of interest was remained at which active site was present, after deleting all unnecessary chains this file was saved as pdb format (Studio 2008).

\section{b) Energy minimization by CHIMERA}

The step of energy minimization and addition of hydrogen atoms is very crucial to obtain more stable conformer and to improve the local interaction in system (Pettersen et al. 2004). Already preprocessed file was loaded in UCSF CHIMERA by using directory. At first dock prep window was opened by using structure analysis option from tools section. Afterwards by clicking ok on dock prep window, another window was opened from which hydrogen atoms was added which lead to the opening of last window. To minimize energy and addition of charges AMBER 
forcefield (AMBER ff14SB) and Gasteiger residue options was used respectively. The files we got was saved in PDB format.

\subsubsection{Docking process}

The redocking procedure was done by loading already prepared protein in PyRx. By using import option 2Dconformer of ligand was imported in SDF format. Before docking energy minimization of ligand was also done by using Universal force field (UFF) along with the conjugate gradient algorithm and total of 500 steps. Both molecules then converted in pdbqt format. In the last the Grid Box was arranged around active site of protein by using vina wizard option so that software only dock and search for maximum score in particular area within box. The docking result was obtained by using start option.

\subsection{Simulation using VMD/NAMD}

MD simulation was performed by using NAMD (Nanoscale Molecular Dynamics) to evaluate binding interactions of ligands with protein $6 \mathrm{M} 2 \mathrm{~N}$. Already docked complexes with highest score are used for molecular dynamic simulation. NAMD software uses CHARMM36 force field (Phillips et al. 2005). Simulation of 1ns (nanosecond) is performed which is of 500,000 steps. Conjugate gradient method was used for energy minimization. Energy minimization was performed for 1000 steps by fixing the backbone atoms. Constant Temperature of $310 \mathrm{~K}$ and pressure of 1ATM was used for the simulation of energy minimized structure using Periodic Boundary conditions. For further analysis the atomic coordinates of simulated structures were recorded at every $0.1 \mathrm{ps}$.

For MD simulation already docked complex must be modified, the coordinates of ligand with best pose (highest score) were inserted in protein file. Topologies of both protein and ligand were made after separating these two molecules from modified complexes by using VMD (Visual Molecular Dynamics) (Humphrey et al. 1996). This topology formation step was done to define atom types, bonds, and angles between atoms as well as the number of molecules in the simulation system. CHARMM-GUI web server were used to build Simulation inputs for ligand with CHARMM36 force field. Automatic PSF Generation within VMD program was used to convert Protein structure into Protein Structure File (PSF). By Merging both files after topology formation, solvation was performed to generate cubic water box around complex. By adjusting parameters ( time, temperature, pressure, energy minimization steps and Periodic Boundary conditions) the final command of simulation was run on windows powershell by using NAMD software.

\section{Results}

\subsection{Docking Scores with MOE}

\subsubsection{Olea europaea}

Molecular docking was done to estimate the ligand-protein interaction between different compounds of herbs and protein (main protease). The chance of ligand to be an effective drug increases with decrease of binding energy. The docking score of Olea europaea is given in (Table 4).

Table 4 Docking score Olive's compounds with 6M2N

\begin{tabular}{llc}
\hline SN & \multicolumn{1}{c}{ Ligands } & $\begin{array}{c}\text { Docking score (kcal/mol) } \\
\text { with 6M2N }\end{array}$ \\
\hline 1 & Neuzhenide & -10.9176493 \\
2 & Demethyloleoeuropein & -9.48762321 \\
3 & Rutin & -9.49832058 \\
4 & Oleuropein & -9.21493816 \\
5 & Luteolin 7-rutinoside & -9.18656158 \\
6 & Ligstroside & -8.72711468 \\
7 & Verbascoside & -8.5100832 \\
8 & Luteolin-7-glucoside & -7.68533516 \\
\hline
\end{tabular}




\begin{tabular}{clc}
\hline 9 & Cosmosin & -7.67128038 \\
10 & luteolin-4'-o-glucoside & -7.25527763 \\
11 & Chlorogenic acid & -6.8014946 \\
12 & Deacetoxyoleuropein aglycone & -6.75398064 \\
13 & Leutolin & -6.27251291 \\
14 & Apigenin & -6.2212038 \\
15 & Quercetin & -6.00290871 \\
16 & Cinamic acid & -5.72288179 \\
17 & Sinapic acid & -5.69604254 \\
18 & Ferulic acid & -5.44703674 \\
19 & Homovanillic acid & -5.18638182 \\
20 & Flavylium & -5.05841064 \\
21 & Vanillic acid & -4.89071226 \\
22 & Hydroxytyrosol & -4.70743608 \\
23 & 4-hydroxybenzoic & -4.65060616 \\
24 & Protocatehuic acid & -4.69090509 \\
25 & Tyrosol & -4.5343833 \\
\hline
\end{tabular}

Graphical representation of scores of Olea europaea compounds are shown in Fig 5.

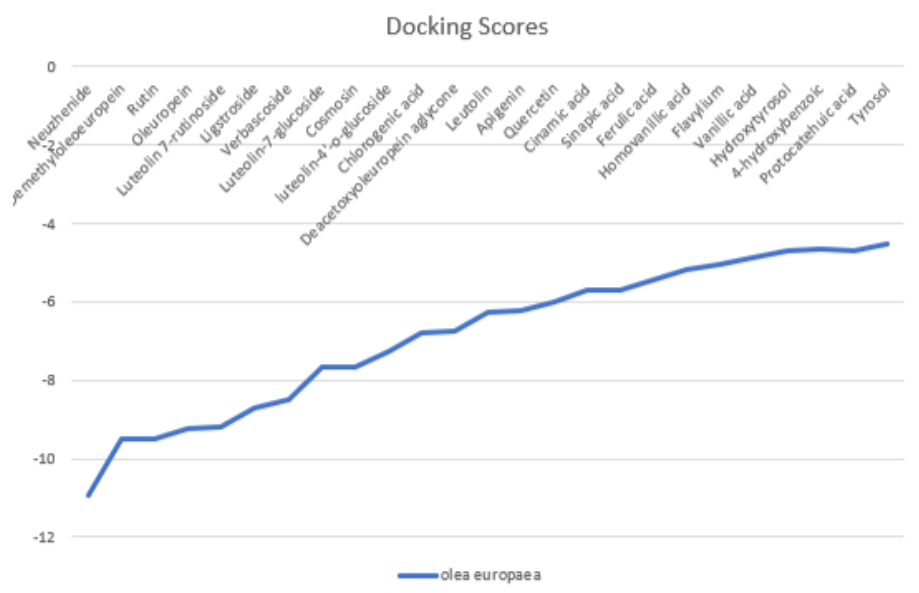

Fig. 5 Graphical representation of Olea europaea compounds scores

\subsubsection{Curcuma Longa}

The docking scores and graphical representation of curcuma's longa compounds are given in (Table 5) and Fig. 6 respectively. Curcumin gave the highest score with the binding energy of $-7.6 \mathrm{kcal} / \mathrm{mol}$. It is followed by Tetrahydrocurcumin and Demethoxycurcumin having energies of -7.4 and -7.02 respectively. Criteria based on docking scores selects the best compounds.

Table 5 Docking score Turmeric's compounds with 6M2N

\begin{tabular}{clc}
\hline SN & \multicolumn{1}{c}{ Ligands } & $\begin{array}{c}\text { Docking score }(\mathbf{k c a l} / \mathbf{m o l}) \\
\text { with 6M2N }\end{array}$ \\
\hline 1 & Curcumin & -7.65329599 \\
2 & Tetrehydrocurcumin & -7.42297649 \\
3 & Demethoxycurcumin & -7.02905893 \\
4 & Bidemethoxycurcumin & -6.77281666 \\
5 & Ar-Turmerone & -5.70936966 \\
\hline
\end{tabular}




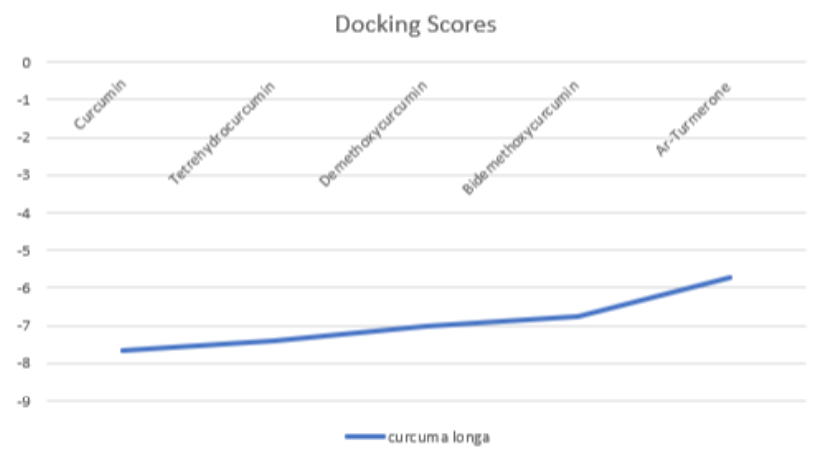

Fig. 6 Graphical representation of Curcuma longa compounds scores

\subsection{Redocking scores with PyRx}

For validation of docking protocol by MOE, redocking of crystal ligand with protein receptor $(6 \mathrm{M} 2 \mathrm{~N})$ was done by PyRx. Only ligands which gave the maximum results with Mpro by using MOE was redocked. Here we chose 15 ligands of olea europaea and 4 ligands of curcuma longa for further analysis. The redocking results are shown in (Table 6).

Table 6 Redocking results with PyRx

\begin{tabular}{clc}
\hline SN & \multicolumn{1}{c}{$\begin{array}{c}\text { Ligands of Olive } \\
\text { and turmeric }\end{array}$} & Results by PyRx \\
\hline 1 & Neuzhenide & -9.4 \\
2 & Demethyloleoeuropein & -8.1 \\
3 & Rutin & -9.5 \\
4 & Oleuropein & -6.6 \\
5 & Luteolin 7-rutinoside & -9.9 \\
6 & Ligstroside & -8.2 \\
7 & Verbascoside & -9.2 \\
8 & Luteolin-7-glucoside & -9.2 \\
9 & Cosmosin & -8.8 \\
10 & luteolin-4'-o-glucoside & -8.4 \\
11 & Chlorogenic acid & -7.6 \\
12 & Deacetoxyoleuropein aglycone & -6.1 \\
13 & Leutolin & -7.9 \\
14 & Apigenin & -7.6 \\
15 & Quercetin & -8.3 \\
16 & Curcumin & -7.2 \\
17 & Tetrehydrocurcumin & -6.8 \\
18 & Demethoxycurcumin & -6.5 \\
19 & Bidemethoxycurcumin & -7 \\
\hline
\end{tabular}

\subsection{Relationship of Lipinski's Rule and Ligand}

According to Lipinski's rule of 5, the ligand which follows 2 or more rules can be considered as a good drug (Benet et al. 2016). We used the SwissADME tool (http://www.swissadme.ch/index.php) to determine how many ligands (which we used) in docking study were following Lipinski' rule.

\subsubsection{Negation to Lipinski's Rule}

There are total 7 ligands (Neuzhenide, Demethyloleoeuropein, Rutin, Oleuropein, Luteolin 7-rutinoside, Verbascoside) which violate 3 rules, but their energies range from -10 to -8.5 (-10.9176493, -9.48762321, $9.49832058,-9.21493816,-9.18656158,-8.5100832$ respectively). The ligands shown in (Table 7) don't follow the Lipinski's rule. 
Table 7 Ligands which do not follow Lipinski's rule

\begin{tabular}{|c|c|c|c|c|c|c|c|}
\hline $\begin{array}{l}\text { PubChem } \\
\text { ID }\end{array}$ & Ligands & $\begin{array}{c}\text { Molecular } \\
\text { weight } \\
\text { (<500Da) }\end{array}$ & $\begin{array}{c}\log P \\
(<5)\end{array}$ & $\begin{array}{l}\text { H-Bond } \\
\text { donor (5) }\end{array}$ & $\begin{array}{l}\text { H-bond } \\
\text { acceptor } \\
(<10)\end{array}$ & Violations & $\begin{array}{l}\text { Docking } \\
\text { score }\end{array}$ \\
\hline 6440999 & Neuzhenide & 686.7 & -2.2 & 8 & 17 & 3 & -10.9176493 \\
\hline 6450302 & Demethyloleoeuropein & 526.49 & -0.8 & 7 & 13 & 3 & -9.48762321 \\
\hline 5280805 & Rutin & 610.5 & -1.3 & 10 & 16 & 3 & -9.49832058 \\
\hline 5281544 & Oleuropein & 540.5 & -0.4 & 6 & 13 & 3 & -9.21493816 \\
\hline 12315422 & Luteolin 7-rutinoside & 595.5 & -1.1 & 9 & 15 & 3 & -9.18656158 \\
\hline 354009 & Verbascoside & 624.5 & -0.5 & 9 & 15 & 3 & -8.5100832 \\
\hline
\end{tabular}

\subsubsection{Ligands under Lipinski’s Rule}

There are total 24 ligands which follow Lipinski's rule of 5 and their energies range from -8.7 to -4.5 . The drug scanning results show that all tested compounds in this study were accepted according to Lipinski's rule of five. Ligands which follow this rule are given in (Table 8).

Table 8 Ligands which follow Lipinski's rule

\begin{tabular}{|c|c|c|c|c|c|c|c|}
\hline $\begin{array}{c}\text { PubChem } \\
\text { ID }\end{array}$ & Ligands & $\begin{array}{l}\text { Molecular } \\
\text { weight } \\
\text { (<500Da) }\end{array}$ & $\begin{array}{c}\log P \\
(<5)\end{array}$ & $\begin{array}{l}\text { H-Bond } \\
\text { donor (5) }\end{array}$ & $\begin{array}{l}\text { H-bond } \\
\text { acceptor } \\
(<10)\end{array}$ & Violations & $\begin{array}{l}\text { Docking } \\
\text { score }\end{array}$ \\
\hline 14136859 & Ligstroside & 524.5 & -0.1 & 5 & 11 & 2 & -8.72711468 \\
\hline 5280637 & Luteolin-7-glucoside & 448.4 & 0.5 & 7 & 11 & 2 & -7.68533516 \\
\hline 5280704 & Cosmosin & 432.4 & -0.1 & 6 & 10 & 1 & -7.67128038 \\
\hline 5319116 & luteolin-4'-o-glucoside & 448.4 & 0.5 & 7 & 11 & 2 & -7.25527763 \\
\hline 1794427 & Chlorogenic acid & 354.31 & -0.4 & 6 & 9 & 1 & -6.8014946 \\
\hline 101102227 & $\begin{array}{l}\text { Deacetoxyoleuropein } \\
\text { aglycone }\end{array}$ & 320 & 1.1 & 2 & 6 & 0 & -6.75398064 \\
\hline 5280445 & Leutolin & 286.23 & 1.4 & 4 & 6 & 0 & -6.27251291 \\
\hline 5280443 & Apigenin & 270.24 & 1.7 & 3 & 5 & 0 & -6.2212038 \\
\hline 5280343 & Quercetin & 302.23 & 1.5 & 5 & 6 & 0 & -6.00290871 \\
\hline 5372020 & Cinamic acid & 255.54 & -0.6 & 2 & 5 & 0 & -5.72288179 \\
\hline 637775 & Sinapic acid & 224.21 & 1.5 & 2 & 5 & 0 & -5.69604254 \\
\hline 445858 & Ferulic acid & 194.18 & 1.5 & 2 & 4 & 0 & -5.44703674 \\
\hline 1738 & Homovanillic acid & 182.17 & 0.4 & 2 & 4 & 0 & -5.18638182 \\
\hline 145858 & Flavylium & 207.25 & 0 & 0 & 1 & 0 & -5.05841064 \\
\hline 8468 & Vanillic acid & 168.15 & 1.4 & 2 & 4 & 0 & -4.89071226 \\
\hline 82755 & Hydroxytyrosol & 154,16 & -0.7 & 3 & 3 & 0 & -4.70743608 \\
\hline 135 & 4-hydroxybenzoic & 138.12 & 1.6 & 2 & 3 & 0 & -4.65060616 \\
\hline 72 & Protocatehuic acid & 154.12 & 1.1 & 3 & 4 & 0 & -4.69090509 \\
\hline 10393 & Tyrosol & 138.16 & 0.4 & 2 & 2 & 0 & -4.5343833 \\
\hline 969516 & Curcumin & 368.4 & 3.2 & 2 & 6 & 0 & -7.65329599 \\
\hline 124072 & Tetrehydrocurcumin & 372.4 & 2.8 & 2 & 6 & 0 & -7.42297649 \\
\hline 5469424 & Demethoxycurcumin & 338.4 & 3,2 & 2 & 5 & 0 & -7.02905893 \\
\hline 5315472 & Bidemethoxycurcumin & 308.4 & 3.3 & 2 & 4 & 0 & -6.77281666 \\
\hline 160512 & Ar- turmerone & 216.32 & 4 & 0 & 1 & 0 & -5.70936966 \\
\hline
\end{tabular}

\subsection{Ligands with Best Binding Energies}

When docked, the ligand attached to the active site of $3 \mathrm{CL}^{\mathrm{pro}} / \mathrm{M}^{\mathrm{pro}}$ and can be visualized by ligand and interaction module for 2D structure and surface and maps module for 3D structure of MOE. Docking results from (Table 4 and 
5) show Neuzhenide from olive and Curcumin from turmeric give the lowest energy i.e. ( $-10.9176493 \mathrm{Kcal} / \mathrm{mol})$ and (-7.65329599) respectively. Through MOE ligand interactions module, the binding pattern can be visualized.

\subsubsection{Best Ligands of Olea europaea}

Neuzhenide, when docked with 6M2N, showed two hydrogen possible interactions with amino acid LEU B282 (Hdonor) with distance of $2.85 \mathrm{~A}^{\circ}$ and energy of -1.4 and amino acid GLU B288 (H-donor) with distance of $2.89 \mathrm{~A}^{\circ}$ and energy of $-0.9 \mathrm{kcal} / \mathrm{mol}$ shown in Fig. 7.

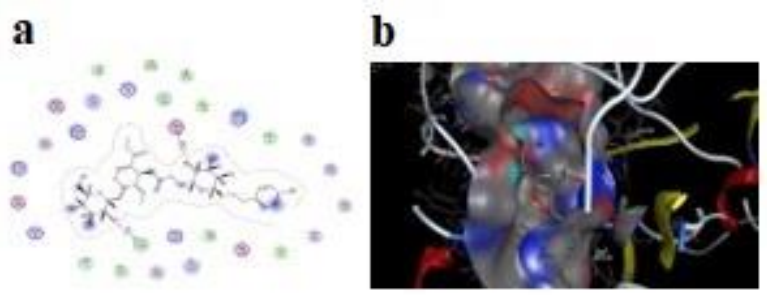

Fig. 7 a Ligand interaction of $6 \mathrm{M} 2 \mathrm{~N}$ with Neuzhenide $\mathbf{b} 3 \mathrm{D}$ diagram of pocket $6 \mathrm{M} 2 \mathrm{~N}$ with Neuzhenide

The interaction usually describes that how much a ligand can form a stabilized bond with target protein. Low binding energy leads to the formation of stabilized bond which give possibility for ligand to be an effective inhibitor. Interaction of other major ligands of Olea europaea whom energies range from -10 to -6 are given in (Table 9).

Table 9 Interaction of major ligands of Olive

Demethyloleoeuropein

Four hydrogen interaction are possible (a) Amino acid PHE 3 (H-donor) distance $3.06 \mathrm{~A}^{0}$ and energy of $-0.9 \mathrm{kcal} / \mathrm{mol}$ (b) Amino acid LEU 282 (H-donor) distance $2.97 \mathrm{~A}^{0}$ and energy of $2.1 \mathrm{kcal} / \mathrm{mol}$ (c) Amino acid GLU 288 (H-donor) distance $2.87 \mathrm{~A}^{0}$ and energy of $-1.7 \mathrm{kcal} / \mathrm{mol}$ (d) Amino acid LYS $137(\pi-\mathrm{H})$ distance $3.84 \mathrm{~A}^{0}$ and energy of $-0.7 \mathrm{kcal} / \mathrm{mol}$

Rutin

Six hydrogen interactions are possible (a) Amino acid LEU 282 (H-donor) distance $3.44 \mathrm{~A}^{0}$ and energy $-0.7 \mathrm{kcal} / \mathrm{mol}$ (b) Amino acid GLU 288 (H-donor) distance $2.80 \mathrm{~A}^{0}$ and energy $-4.1 \mathrm{kcal} / \mathrm{mol}$ (c) Amino acid ASP 289 (H-donor) distance $3.06 \mathrm{~A}^{0}$ and energy $-2.3 \mathrm{kcal} / \mathrm{mol}$ (d) Amino acid GLU 288 (H-donor) distance $2.75 \mathrm{~A}^{0}$ and energy $-1.5 \mathrm{kcal} / \mathrm{mol}$ (e) Amino acid TRP 207 (H-acceptor) distance $3.13 \mathrm{~A}^{0}$ and energy $-1.3 \mathrm{kcal} / \mathrm{mol}$ (f) Amino acid LYS $5 \mathrm{H}$-acceptor distance $2.80 \mathrm{~A}^{0}$ and energy $-1.7 \mathrm{kcal} / \mathrm{mol}$

\section{Oleuropein}




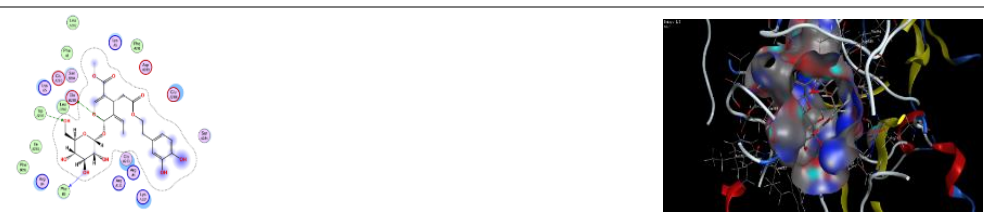

Three hydrogen interactions are possible (a) Amino acid GLU $288\left(\mathrm{H}\right.$-donor) distance $3.38 \mathrm{~A}^{0}$ and energy $-1.0 \mathrm{kcal} / \mathrm{mol}$ (b) Amino acid PHE 3 (H-donor) distance $2.63 \mathrm{~A}^{0}$ and energy $-2.7 \mathrm{kcal} / \mathrm{mol}$ (c) Amino acid TRP 207 ( $\mathrm{H}$-acceptor) distance $2.87 \mathrm{~A}^{0}$ and energy $-1.8 \mathrm{kcal} / \mathrm{mol}$

Luteolin 7-rutinoside

Five type of hydrogen interactions are possible (a) Amino acid LEU 287 (H-donor) distance $2.83 \mathrm{~A}^{0}$ energy of $-0.7 \mathrm{kcal} / \mathrm{mol}$ (b) Amino acid GLU 288 (H-donor) distance $2.93 \mathrm{~A}^{0}$ energy of $1.4 \mathrm{kcal} / \mathrm{mol}$ (c) Amino acid GLU 288 (H-donor) distance $2.80 \mathrm{~A}^{0}$ energy of $-3.4 \mathrm{kcal} / \mathrm{mol}$ (d) Amino acid GLU 288 (H-donor) distance $3.00 \mathrm{~A}^{0}$ energy of $-1.4 \mathrm{kcal} / \mathrm{mol}$ (e) Amino acid ARG $4(\mathrm{H}$ acceptor) distance $3.34 \mathrm{~A}^{0}$ energy of $-1.2 \mathrm{kcal} / \mathrm{mol}$

acceptor) distance 3.34A energy of $-1.2 \mathrm{kcal} / \mathrm{mol}$
Ligstroside

Four types of hydrogen interactions are possible (a) Amino acid GLU 288 (H-donor) distance $3.26 \mathrm{~A}^{0}$ energy of $-0.8 \mathrm{kcal} / \mathrm{mol}$ (a) Amino acid GLU 288 (H-donor) distance $2.87 \mathrm{~A}^{0}$ energy of $4.0 \mathrm{kcal} / \mathrm{mol}$ (b) Amino acid ASP 197 (H-donor) distance $3.11 \mathrm{~A}^{0}$ energy $-1.3 \mathrm{kcal} / \mathrm{mol}$ (c) Amino acid LYS 5 (H-acceptor) distance $3.04 \mathrm{~A}^{0}$ energy $-4.7 \mathrm{kcal} / \mathrm{mol}$

Verbascoside

Five types of hydrogen interactions are possible (a) Amino acid GLU 14 (H-donor) distance $3.06 \mathrm{~A}^{0}$ energy of $-1.5 \mathrm{kcal} / \mathrm{mol}$ (b) Amino acid GLU 14 (H-donor) distance $2.75 \mathrm{~A}^{0}$ energy of $4.5 \mathrm{kcal} / \mathrm{mol}$ (c) Amino acid GLU 14 (H-donor) distance $2.83 \mathrm{~A}^{0}$ energy of $-2.0 \mathrm{kcal} / \mathrm{mol}$ (d) Amino acid LYS 12 (H-acceptor) distance $3.23 \mathrm{~A}^{0}$ energy of $-3.4 \mathrm{kcal} / \mathrm{mol}(\mathrm{e})$ Amino acid LYS $97(\mathrm{H}$ acceptor) distance $3.24 \mathrm{~A}^{0}$ energy of $-1.2 \mathrm{kcal} / \mathrm{mol}$

Luteolin-7-glucoside

Three types of hydrogen interaction are possible (a) Amino acid GLU 288 (H-donor) distance $2.81 \mathrm{~A}^{0}$ energy of $-4.4 \mathrm{kcal} / \mathrm{mol}$ (b) Amino acid GLU 288 ( $\mathrm{H}$-donor) distance $3.14 \mathrm{~A}^{0}$ energy of $2.4 \mathrm{kcal} / \mathrm{mol}$ (c) Amino acid LEU 287 (H-donor) distance $2.94 \mathrm{~A}^{0}$ energy of $-1.0 \mathrm{kcal} / \mathrm{mol}$ 

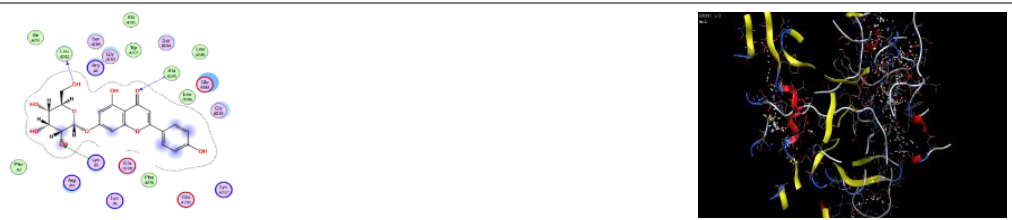

Three hydrogen interactions are possible (a) Amino acid LEU 282 (H-donor) distance 2.87 $\mathrm{A}^{0}$ energy of $-1.2 \mathrm{kcal} / \mathrm{mol}$ (b) Amino acid ALA 285 (H-acceptor) distance $3.41 \mathrm{~A}^{0}$ energy of $0.9 \mathrm{kcal} / \mathrm{mol}$ (c) Amino acid LYS 5 (H-acceptor) distance $3.34 \mathrm{~A}^{0}$ energy of $-0.5 \mathrm{kcal} / \mathrm{mol}$

Luteolin-4'-o-glucoside

One type of hydrogen interaction is possible (a) Amino acid LYS 5 ( $\mathrm{H}$-acceptor) distance 3.29 $\mathrm{A}^{0}$ energy of $-1.1 \mathrm{kcal} / \mathrm{mol}$

Chlorogenic acid

Three types of hydrogen interactions are possible (a) Amino acid GLU 288 (H-donor) distance $3.59 \mathrm{~A}^{0}$ energy of $-0.7 \mathrm{kcal} / \mathrm{mol}$ (b) Amino acid GLY 138 (H-donor) distance $3.06 \mathrm{~A}^{0}$ energy of $2.5 \mathrm{kcal} / \mathrm{mol}$ (c) Amino acid LYS 5 (H-acceptor) distance $3.27 \mathrm{~A}^{0}$ energy of $-0.6 \mathrm{kcal} / \mathrm{mol}$

\section{Deacetoxyoleuropein aglycone}

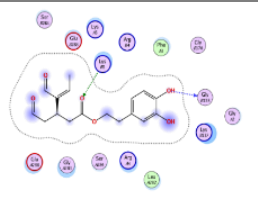

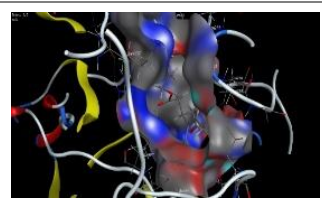

Two types of hydrogen interactions are possible (a) Amino acid GLY 138 (H-donor) distance $3.11 \mathrm{~A}^{0}$ energy of $-2.4 \mathrm{kcal} / \mathrm{mol}$ (b) Amino acid LYS 5 (H-acceptor) distance $3.06 \mathrm{~A}^{0}$ energy of $1.6 \mathrm{kcal} / \mathrm{mol}$

Leutolin

one type of hydrogen interaction is possible (a) Amino acid HIS $41(\pi-\pi)$ distance $3.83 \mathrm{~A}^{0}$ energy of $-0.0 \mathrm{kcal} / \mathrm{mol}$

No perceptible interactions, only electrostatics exist (Van der Waals)




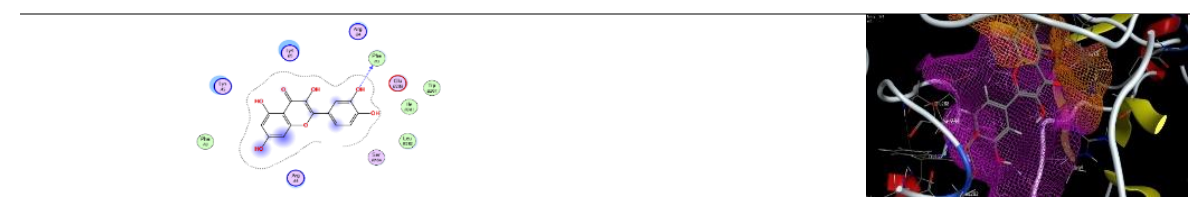

one type of hydrogen interaction is possible (a) Amino acid PHE 3 (H-donor) distance $2.92 \mathrm{~A}^{0}$ energy of $-1.7 \mathrm{kcal} / \mathrm{mol}$

\subsubsection{Best Ligands of Curcuma longa}

Curcumin, when docked with $6 \mathrm{M} 2 \mathrm{~N}$, showed one hydrogen possible interaction with amino acid GLU C290 with distance of $2.83 \mathrm{~A}^{\circ}$ and energy of $-0.8 \mathrm{kcal} / \mathrm{mol}$. This interaction is shown in Fig. 8.

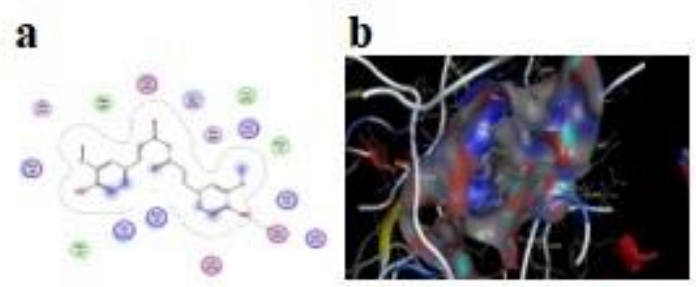

Fig. 8 a Ligand interaction of $6 \mathrm{M} 2 \mathrm{~N}$ with Curcumin b 3D diagram of pocket $6 \mathrm{M} 2 \mathrm{~N}$ with Curcumin

Curcuma longa ligands gave the lower score as compared to major Olea europaea compounds. But these ligands have great potential to inhibit viral activity of SARS-nCOV2. The interactions of major ligands of Curcuma longa (other than curcumin) whom energies are from -7 to -6 are given in (Table 10).

Table 10 Interaction of major ligands of Turmeric

Tetrehydrocurcumin

Two types of hydrogen interactions are possible (a) Amino acid GLU 290 (H-donor) distance $2.86 \mathrm{~A}^{0}$ energy $-2.6 \mathrm{kcal} / \mathrm{mol}$ (a) Amino acid LYS 5 (H-acceptor) distance $3.30 \mathrm{~A}^{0}$ energy $1.4 \mathrm{kcal} / \mathrm{mol}$

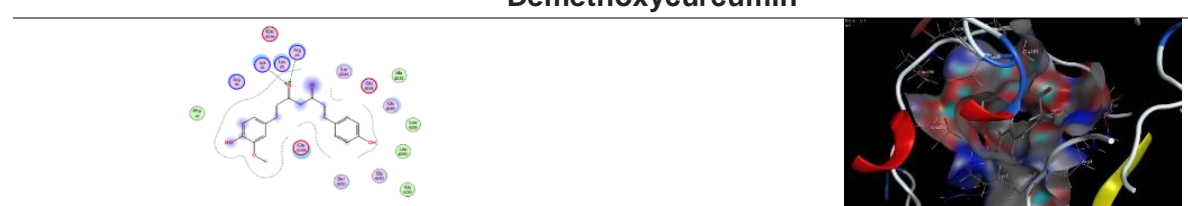

Demethoxycurcumin

Two types of hydrogen interactions are possible (a) Amino acid LYS A5 (H-accepter) distance $2.53 \mathrm{~A}^{0}$ energy of $-1.3 \mathrm{kcal} / \mathrm{mol}$ (b) Amino acid ARG B4 (H-accepter) distance $2.3 \mathrm{~A}^{0}$ energy of $1.2 \mathrm{kcal} / \mathrm{mol}$ 

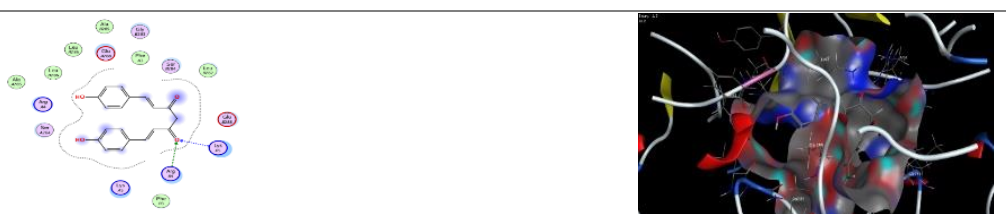

Two types of hydrogen interactions are possible (a) Amino acid LYS B5 (H-accepter) distance $2.1 \mathrm{~A}^{0}$ energy of $-0.9 \mathrm{kcal} / \mathrm{mol}$ (b) Amino acid LYS B4 (H-accepter) distance $1.9 \mathrm{~A}^{0}$ energy of $1.4 \mathrm{kcal} / \mathrm{mol}$

\section{Molecular Dynamic Simulation Analysis}

Molecular dynamic simulation was performed to evaluate the stability of structure obtained from molecular docking studies. The analysis of molecular dynamic simulation was subjected to ligands which gave highest score with docking and redocking. By comparing the results of docking from both MOE and PyRx, we screened 5 complexes (ligand with Mpro) (Neuzhenide, Demethyloleoeuropein, Rutin, Oleuropein, Luteolin 7-rutinoside) of olea europaea and 2 complexes (Curcumin, Tetrehydrocurcumin) of curcuma longa for simulation. This evaluation with simulation was performed for $1 \mathrm{~ns}$. The aim of this simulation was to check whether the docked poses in highest scored complexes remained stable.

\subsection{RMSD calculation}

RMSD (root mean square deviation) calculations was done to measures the average distance between groups of atoms. This was done by using VMD (Visual Molecular Dynamics). The RMSD plot of olea europaea complexes shown in figure. Demethyloleoeuropein RMSD plot shows that docked complex remained stable from 270 frames to 3000 frames (nearly $0.25 \mathrm{~ns}$ to $0.75 \mathrm{~ns}$ ) at $2 \AA$, then slightly increased and become persistent at $2.5 \AA$ from 3000 frames till end of run. Results of Rutin complex indicates that the complex reaches stability at $2 \AA$ from 200 frames till 1300 frames of the simulation, the RMSD value decrease up to $1.5 \AA$ and again becomes stable till the end of run. RMSD graph of oleuropein remain nearly same as Rutin where it got stable for short intervals at $1.5 \AA$ then it its value decreases to $1.25 \AA$ and deviate at the end of simulation. The plot of last two complexes Luteolin 7 rutinoside and Neuzhenide keep on fluctuating irregularly and remain stable for short interval of time between 1750 frames to 2750 frames at $1.5 \AA$ and from 1100 frames to 2100 frames at $1.5 \AA$ respectively.

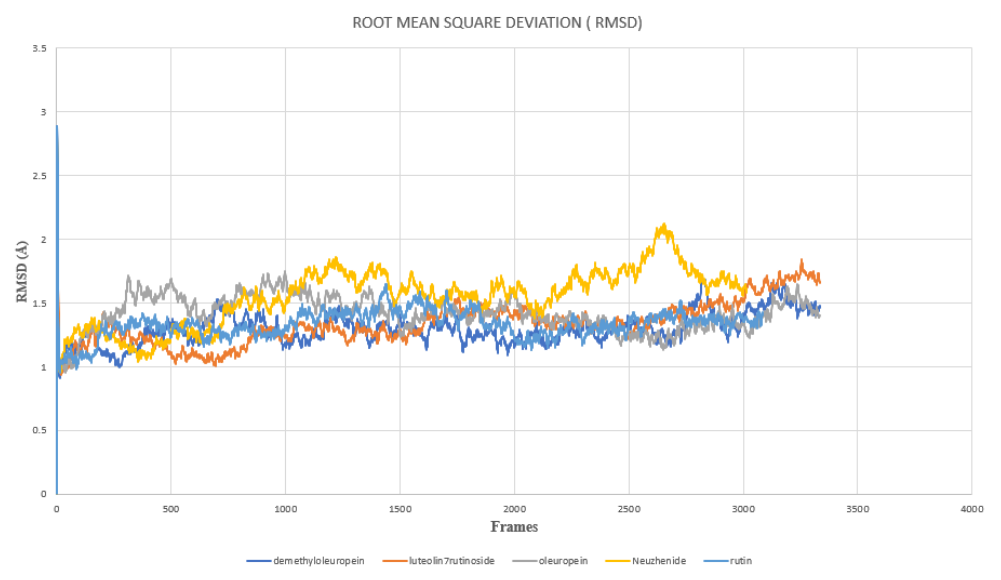

Fig. 9 RMSD graph of olea europaea docked complex

The RMSD plot of curcuma longa complexes are shown in figure, where graph of docked complex Tetrahydrocurcumin remained stable throughout the course of simulation at $1.25 \AA$, a slight deviation is seen at the end where is decrease to $1.1 \AA$. The plot of curcumin only has slight variation in start with continuously increasing, after that it remain stable at the end at $1.5 \AA$. 


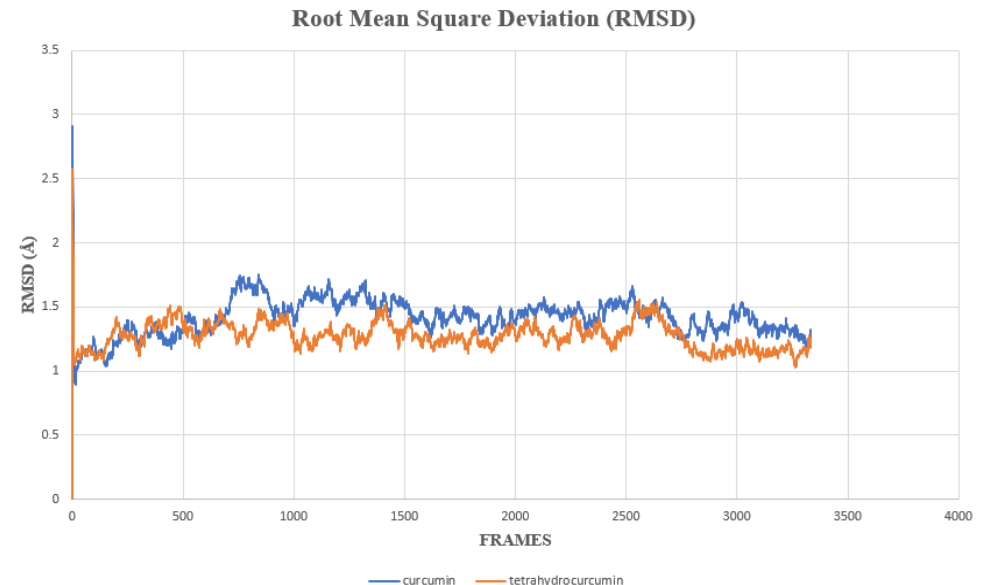

Fig. 10 RMSD plot of curcuma longa docked complex

\subsection{H-bond analysis}

Hydrogen bond analysis during molecular dynamic simulation complexes of olea europaea and curcuma longa are shown in figures respectively. The gap between two residues are reduced by the formation of strong hydrogen bond with water. In Demethyloleoeuropein complex of olea europaea, total 13 hydrogen bonds are formed, major hydrogen bond which is responsible for stabilization of complex make occupancy rate of $69 \%$ and between major ligand (act as donor) and aspartic acid ASP-289 (act as receptor). In simulation of Luteolin 7-rutinoside out of 20 hydrogen bonds, bond with ligand (ligand) and glutamic acid GLU288 (acceptor) with occupancy rate of 77.39\% is responsible for stabilization. In simulation Oleuropein complex was stable due to formation of hydrogen bond of ligand (donor) and aspartic acid ASP153 (acceptor) which remained 96.28\% of simulation time. Neuzhenide complex was stable by forming hydrogen bond between ligand ( donor) and aspartic acid ASP289-Side (acceptor) and remained stable for $81.74 \%$ of simulation run. Simulation of Rutin complex was stabilized by hydrogen bond of ligand (donor) and aspartic acid ASP289 (acceptor) with the occupancy of 79.68\%. 

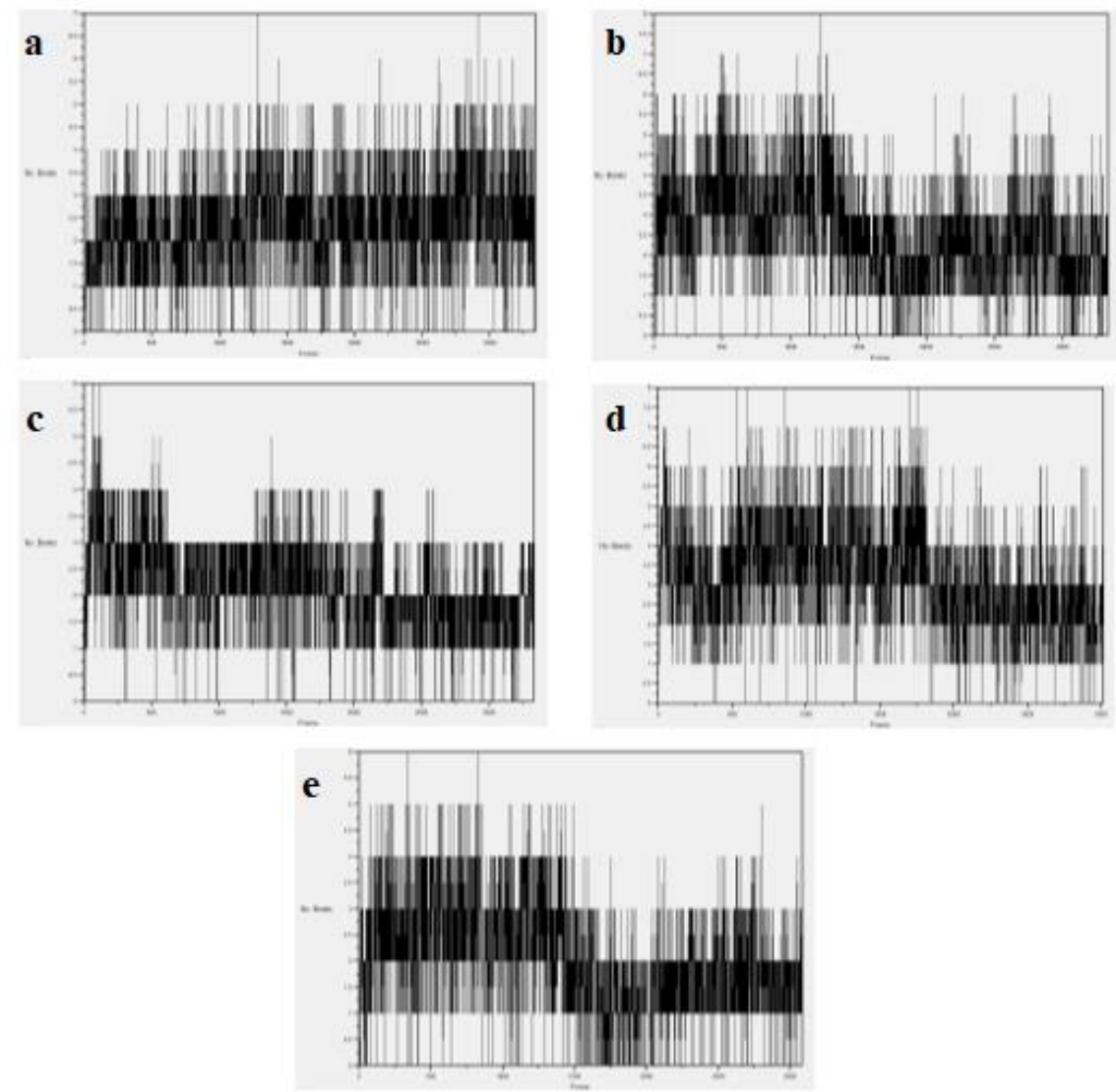

Fig. 11 H-bonds graph of olea europaea docked complex a Demethyloleoeuropein b Luteolin 7-rutinoside c Oleuropein d Neuzhenide e Rutin

While in complexes of curcuma longa, curcumin and Tetrahydrocurcumin got stabilize with $71.90 \%$ bond formation between lysine LYS5-Main (donor) and ligand (acceptor) and 38.74\% bond formation with lysine LYS137-Side (donor) and ligand (receptor) respectively as shown in Fig. 12.
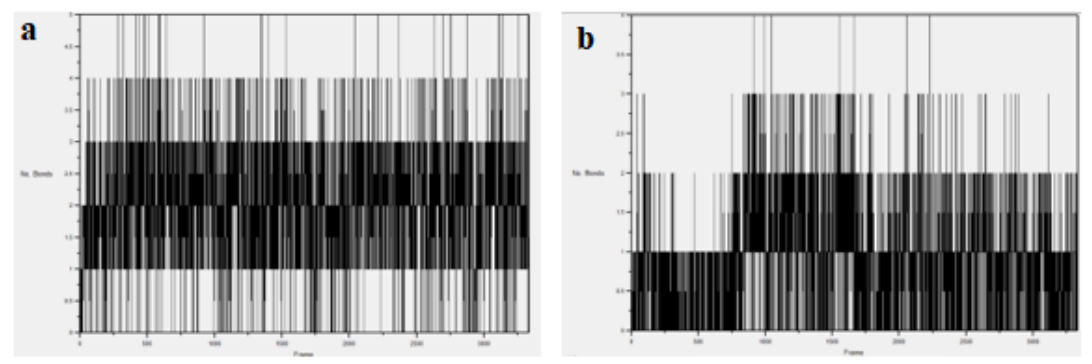

Fig. 12 H-bonds graph of curcuma longa docked complex a Curcumin b Tetrahydrocurcumin

\subsection{Heat map plot}

Heat map of both olea europaea and curcuma longa complexes can be seen in Fig. 13 and 14, made by RMSD visualizer tool built-in feature of VMD, these heat signatures shows the stability of complexes during simulation. In the heatmap graph of Olea europaea complexes Demethyloleoeuropein, Oleuropein and Rutin shows promissing stability where neuzhenide and luteolin-7-rutinoside show low statbility of short intervals. 
a
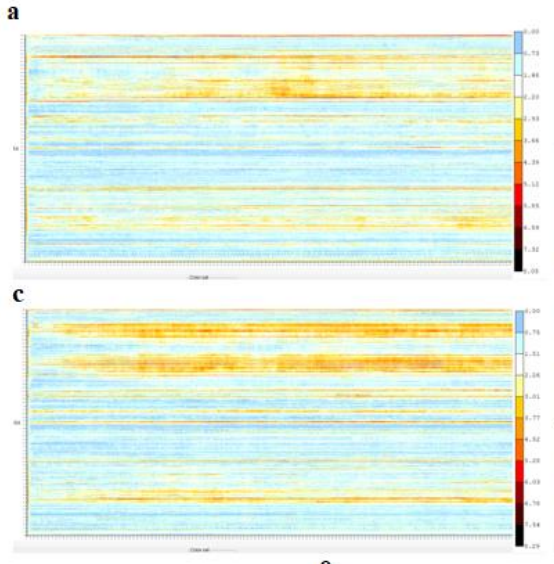

e

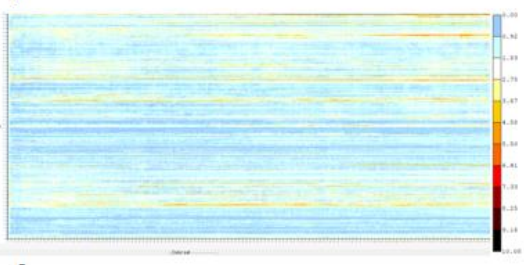

d

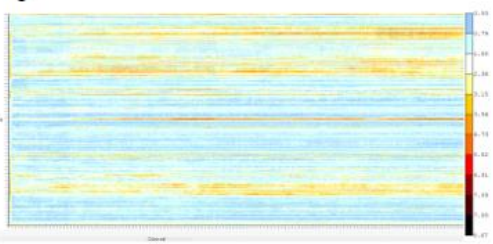

Fig. 13 heat map of olea europaea a Demethyloleoeuropein b Luteolin 7-rutinoside c Oleuropein d Neuzhenide e Rutin

In cursuma longa complexes, curuma is far stable than tetrahydrocurcumin, which has low stability.
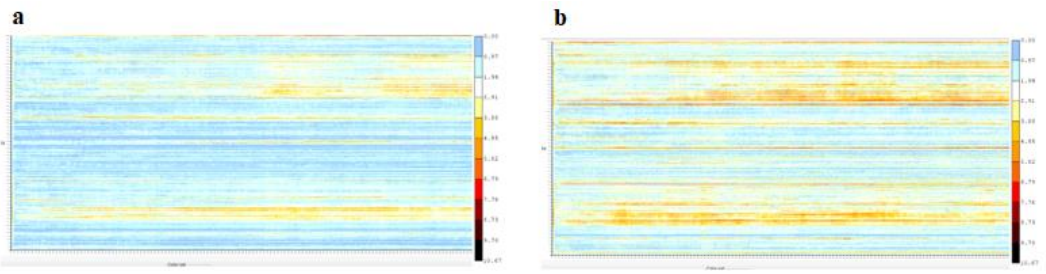

Fig. 14 heat map of curcuma longa a Curcumin b Tetrahydrocurcumin

\section{Discussion}

To our knowledge, this kind of drug finding research on COVID-19 is limited. A number of barriers have been identified and out of these barriers, the most prominent one is mutation (Pachetti et al. 2020), as SARS-nCoV2 is RNA virus that mutates very quickly making its drug or vaccine less affective (Burton and Walker 2020). The present study focuses on finding potential drug of SARS-nCoV2 using docking study and molecular dynamic simulation. The main protein target here is SARS-nCoV2 main protease $\left(\mathrm{M}^{\mathrm{pro}} / 3 \mathrm{cl}\right.$-protease) which is required for viral replication and maturation. By blocking this protein, the further replication of virus can be halted.

Major findings are Rutin, Demethyloleoeuropein and Oleuropein from natural source of olea europaea and Curcumin from curcuma longa which after docking, redocking and molecular dynamic studies gave lowest energy as compare to other ligands that form stable protein-ligand complex with lowest energy by accurately fitting in active site of M-protease and forming the maximum hydrogen bonds, also made the most stable complex with Mprotease during molecular dynamic simulation run. In contrast Neuzhenide and Luteolin-7-rutinoside from Olea europaea and Tetrahydrocurcumin from Curcuma longa also gave the minimum energy but fluctuate randomly and remain stable for short interval during simulation. These findings are important because these compounds can be the potential inhibitors of SARS-nCoV2, as molecular docking and molecular dynamic simulation predicts proteinligand interaction and stability and is used in computer aided drug designing. 
Drugs which are currently recommended in COVID-19 (nelfinavir, remedsivir and hydroxychloroquine) show the ligand-protein interaction docking score of $-9.18 \mathrm{kcal} / \mathrm{mol},-6.3 \mathrm{kcal} / \mathrm{mol}$ and $-5.7 \mathrm{kcal} / \mathrm{mol}$ respectively in different articles (Bouchentouf and Noureddine 2020; Khaerunnisa et al. 2020). The ligands of olive and turmeric gave high docking score and are more stable in comparison to these recommended drugs.

The Neuzhenide, Oleuropein and Demethyloleoeuropein are nontoxic when their properties were checked from SwissADME and can be used without any harmful effects. Oleuropein has antiviral property and is currently used to treat infectious mononucleosis, epidemic jaundice, diarrheal disease, bovine rhinovirus infection, canine parvovirus infection and feline leukemia (Omar 2010). Pharmacological properties of Oleuropein include antiirritant, antiangiogenic, anti-malignancy, antimicrobic and cytoprotective. Rutin, a flavonoid compound, has several biological activities like antiallergic, antitumor, reduce inflammation and antiangiogenic (Ganeshpurkar and Saluja 2017). Luteolin 7-rutinoside has a number of different properties and the most promising ones are antiallergic, antimicrobial, antimutagenic and anticarcinogenic activities (Hewlings and Kalman 2017). Curcuma longa compound Curcumin is a phytopolylphenol pigment, which blocks the formation of reactive-oxygen species and possesses antineoplastic and anti-inflammatory properties (Hewlings and Kalman 2017).

There are few limitations related to Lipinski's rule of drug likeness. As given in table 8 and 9 , there are 6 ligands that do not follow Lipinski's rule, but their scores are between -10 and $-7 \mathrm{kcal} / \mathrm{mol}$ while 24 ligands follow Lipinski's rule, scoring from -7 to $-4 \mathrm{kcal} / \mathrm{mol}$. But several articles reported that Lipinski's rule does not apply on natural products and semisynthetic natural drugs (Zhang and Wilkinson 2007). Furthermore, the recommended drug remedsivir and many other drugs that are currently being used in COVID-19 do not follow Lipinski's rule.

As research in this field is lacking and there is a desperate need to design an effective drug against COVID19 in this pandemic, so Demethyloleoeuropein, Rutin, Oleuropein and curcumin can be the potential inhibitors of COVID-19 as they gave the best docking scores and maximum stability with M-protease. Neuzhenide, , Luteolin 7rutinoside, Ligstroside, Verbascoside, Luteolin-7-glucoside, Curcumin, Tetrehydrocurcumin and Demethoxycurcumin can also be consider for drug designing. As a result, these olive and turmeric ligands are recommended for future research.

\section{Conclusions}

In the current scenario of COVID-19 pandemic, where near to 2.5 million people died and more than 111 million people are affected till now, there is no approved drug against COVID-19. Computer-aided drug designing (CADD) can help to overcome this situation through ligand-protein interaction (docking) and simulation studies. The aim of this study was to examine compounds from olive and turmeric that can be used to inhibit SARS-nCoV2 by acting on one of its enzymes, Main protease (M-pro), which is essential for viral replication. Molecular docking and molecular dynamic simulation results show that Demethyloleoeuropein, Rutin, Oleuropein, Neuzhenide and Curcumin gave the lowest binding energies and stable complex during simulation from olive and turmeric and are the most recommended ones against COVID-19. These suggested inhibitors are necessary to be investigated in further research and clinical trials to determine their action against SARS-nCoV2.

\section{Acknowledgements}

Authors acknowledge the great efforts of the institutes involved in databases and MOE software development.

\section{Compliance with ethical standards}

There is no ethical statement required as raw data was taken from publicly available databases.

\section{Conflict of interests}

The authors declare no conflict of interest. 


\section{References}

(WHO) WHO (2020) covid-19 statistics, https://www.who.int/docs/default-source/coronaviruse/situationreports/20200805-covid-19-sitrep-198.pdf?sfvrsn=f99d1754_2.

Ali SA, Parveen N, Ali AS (2018) Links between the Prophet Muhammad (PBUH) recommended foods and disease management: A review in the light of modern superfoods Int J Health Sci (Qassim) 12:61-69

Benet LZ, Hosey CM, Ursu O, Oprea TI (2016) BDDCS, the Rule of 5 and drugability Adv Drug Deliv Rev 101:8998 doi:10.1016/j.addr.2016.05.007

Bhowmik D, Kumar K, Chandira M, Jayakar B (2008) Turmeric: A Herbal and Traditional Medicine Arch Appl Sci Res 1

Boskou D, Camposeo S, Clodoveo ML (2015) 8 - Table Olives as Sources of Bioactive Compounds. In: Boskou D (ed) Olive and Olive Oil Bioactive Constituents. AOCS Press, pp 217-259. doi:https://doi.org/10.1016/B978-1-63067-041-2.50014-8

Bouchentouf S, Noureddine M (2020) Identification of Compounds from Nigella Sativa as New Potential Inhibitors of 2019 Novel Coronasvirus (Covid-19): Molecular Docking Study. doi:10.26434/chemrxiv.12055716.v1

Brian DA, Baric RS (2005) Coronavirus Genome Structure and Replication. In: Enjuanes L (ed) Coronavirus Replication and Reverse Genetics. Springer Berlin Heidelberg, Berlin, Heidelberg, pp 1-30. doi:10.1007/3540-26765-4_1

Burton DR, Walker LM (2020) Rational Vaccine Design in the Time of COVID-19 Cell Host \& Microbe 27:695698 doi:https://doi.org/10.1016/j.chom.2020.04.022

Chattopadhyay I, Biswas K, Bandyopadhyay U, Banerjee R (2003) Turmeric and Curcumin: Biological actions and medicinal applications Curr Sci 87

Coronaviridae Study Group of the International Committee on Taxonomy of V (2020) The species Severe acute respiratory syndrome-related coronavirus: classifying 2019-nCoV and naming it SARS-CoV-2 Nat Microbiol 5:536-544 doi:10.1038/s41564-020-0695-z

Cucinotta D, Vanelli M (2020) WHO Declares COVID-19 a Pandemic Acta bio-medica : Atenei Parmensis 91:157160 doi:10.23750/abm.v91i1.9397

Dallakyan S, Olson AJ (2015) Small-molecule library screening by docking with PyRx Methods Mol Biol 1263:243-250 doi:10.1007/978-1-4939-2269-7_19

Ganeshpurkar A, Saluja AK (2017) The Pharmacological Potential of Rutin Saudi Pharm J 25:149-164 doi:10.1016/j.jsps.2016.04.025

Ghanbari R, Anwar F, Alkharfy KM, Gilani AH, Saari N (2012) Valuable nutrients and functional bioactives in different parts of olive (Olea europaea L.)-a review International journal of molecular sciences 13:32913340 doi:10.3390/ijms13033291

Hashmi MA, Khan A, Hanif M, Farooq U, Perveen S (2015) Traditional Uses, Phytochemistry, and Pharmacology of $<\mathrm{i}>$ Olea europaea</i> (Olive) Evidence-Based Complementary and Alternative Medicine 2015:541591 doi:10.1155/2015/541591

Hewlings SJ, Kalman DS (2017) Curcumin: A Review of Its' Effects on Human Health Foods 6:92 doi:10.3390/foods6100092

Hui DS et al. (2020) The continuing 2019-nCoV epidemic threat of novel coronaviruses to global health \&\#x2014; The latest 2019 novel coronavirus outbreak in Wuhan, China International Journal of Infectious Diseases 91:264-266 doi:10.1016/j.ijid.2020.01.009

Humphrey W, Dalke A, Schulten KJJomg (1996) VMD: visual molecular dynamics 14:33-38

Jin Z et al. (2020) Structure of Mpro from SARS-CoV-2 and discovery of its inhibitors Nature 582:289-293 doi:10.1038/s41586-020-2223-y

Khaerunnisa S, Kurniawan H, Awaluddin R, Suhartati S, Soetjipto S (2020) Potential Inhibitor of COVID-19 Main Protease (Mpro) From Several Medicinal Plant Compounds by Molecular Docking Study. doi:10.20944/preprints202003.0226.v1

Kupferschmidt K (2013) Emerging diseases. Researchers scramble to understand camel connection to MERS Science (New York, NY) 341:702 doi:10.1126/science.341.6147.702

Lee P-I, Hsueh P-R (2020) Emerging threats from zoonotic coronaviruses-from SARS and MERS to 2019-nCoV J Microbiol Immunol Infect 53:365-367 doi:10.1016/j.jmii.2020.02.001

Li T, Peng T (2013) Traditional Chinese herbal medicine as a source of molecules with antiviral activity Antiviral Research 97:1-9 doi:https://doi.org/10.1016/j.antiviral.2012.10.006

Mengist HM, Fan X, Jin T (2020) Designing of improved drugs for COVID-19: Crystal structure of SARS-CoV-2 main protease Mpro Signal Transduction and Targeted Therapy 5:67 doi:10.1038/s41392-020-0178-y 
Micol V, Caturla N, Pérez-Fons L, Más V, Pérez L, Estepa A (2005) The olive leaf extract exhibits antiviral activity against viral haemorrhagic septicaemia rhabdovirus (VHSV) Antiviral Res 66:129-136 doi:10.1016/j.antiviral.2005.02.005

Niranjan A, Prof D (2008) Chemical constituents and biological activities of turmeric (Curcuma longa L.) -A review Journal of Food Science and Technology 45:109-116

Omar SH (2010) Oleuropein in olive and its pharmacological effects Sci Pharm 78:133-154 doi:10.3797/scipharm.0912-18

Pachetti $\mathrm{M}$ et al. (2020) Emerging SARS-CoV-2 mutation hot spots include a novel RNA-dependent-RNA polymerase variant Journal of Translational Medicine 18:179 doi:10.1186/s12967-020-02344-6

Paraskevis D, Kostaki EG, Magiorkinis G, Panayiotakopoulos G, Sourvinos G, Tsiodras S (2020) Full-genome evolutionary analysis of the novel corona virus (2019-nCoV) rejects the hypothesis of emergence as a result of a recent recombination event Infect Genet Evol 79:104212-104212 doi:10.1016/j.meegid.2020.104212

Peiris JS et al. (2003) Coronavirus as a possible cause of severe acute respiratory syndrome Lancet (London, England) 361:1319-1325 doi:10.1016/s0140-6736(03)13077-2

Pettersen EF, Goddard TD, Huang CC, Couch GS, Greenblatt DM, Meng EC, Ferrin TEJJocc (2004) UCSF Chimera-a visualization system for exploratory research and analysis 25:1605-1612

Phillips JC et al. (2005) Scalable molecular dynamics with NAMD Journal of computational chemistry 26:17811802 doi: $10.1002 /$ jcc.20289

Renu K, Prasanna PL, Valsala Gopalakrishnan A (2020) Coronaviruses pathogenesis, comorbidities and multi-organ damage - A review Life Sci 255:117839-117839 doi:10.1016/j.lfs.2020.117839

Studio DJA (2008) Discovery Studio

Vilar S, Cozza G, Moro S (2008) Medicinal Chemistry and the Molecular Operating Environment (MOE): Application of QSAR and Molecular Docking to Drug Discovery Current topics in medicinal chemistry 8:1555-1572 doi: $10.2174 / 156802608786786624$

Wang T, Du Z, Zhu F, Cao Z, An Y, Gao Y, Jiang B (2020) Comorbidities and multi-organ injuries in the treatment of COVID-19 The Lancet 395:e52 doi:10.1016/S0140-6736(20)30558-4

Xu Z, Peng C, Shi Y, Zhu Z, Mu K, Wang X, Zhu W (2020) Nelfinavir was predicted to be a potential inhibitor of 2019-nCov main protease by an integrative approach combining homology modelling, molecular docking and binding free energy calculation:2020.2001.2027.921627 doi:10.1101/2020.01.27.921627 \%J bioRxiv

Xue X et al. (2008) Structures of Two Coronavirus Main Proteases: Implications for Substrate Binding and Antiviral Drug Design 82:2515-2527 doi:10.1128/JVI.02114-07 \%J Journal of Virology

Yu W, MacKerell AD, Jr. (2017) Computer-Aided Drug Design Methods Methods Mol Biol 1520:85-106 doi:10.1007/978-1-4939-6634-9_5

Zhang MQ, Wilkinson B (2007) Drug discovery beyond the 'rule-of-five' Current opinion in biotechnology 18:478488 doi:10.1016/j.copbio.2007.10.005

Zhu N et al. (2020) A Novel Coronavirus from Patients with Pneumonia in China, 2019 The New England journal of medicine 382:727-733 doi:10.1056/NEJMoa2001017 